\title{
DETERMINANTS OF HEART RATE IN NEWBORNS
}

\author{
Javorka K., Javorka M., Tonhajzerova I., Calkovska A., Lehotska Z.*, \\ Bukovinska Z.*, Zibolen M.*
}

Department of Physiology and *Clinic of Neonatology, Jessenius Faculty of Medicine, Comenius University and University Hospital Martin, Slovakia

\begin{abstract}
This paper presents an overview of cardiac chronotropic regulation determinants in newborns, which are reflected in mean heart rate (HR) and heart rate variability (HRV). Heart rate and heart rate variability in newborns are determined by many factors. Heritability and maturation play major role. Factor of the maturation can be seen in HR and HRV differences between healthy full term and preterm newborns as well as in changes over early postnatal time. These parameters in newborns are influenced also by many other factors as gender, nutrition, sleep, breathing pattern/ventilation, etc.

Autoregulation and extrinsic regulation of cardiac activity has its own specificities in newborns. Homeometric mechanism (depended on HR) is dominant and baroreflex sensitivity is reduced, mainly in premature newborns. Complex cardiac regulation can be studied and evaluated by cardiac reflexes. Examination of the reflexes in newborns is limited. Therefore, new approaches for the study of maturation cardiac control are developed taking into consideration all cardiac activity in newborns determinants.
\end{abstract}

Keywords: newborn, prematurity, heart rate, heart rate variability, regulation of cardiac function, autonomic nervous system, cardiac reflexes

\section{INTRODUCTION}

Newborns for rapid transition from fetal to postnatal life must have properly developed functioning systems including their intrinsic and extrinsic (nervous and humoral) control mechanisms. Everything, even a clinically asymptomatic dysregulation can be followed by a maladaptation with potential serious consequences, that can occur later. Therefore, the research in physiology and neonatology deals with the determinants of cardiac activity, cardiovascular system (CVS) control mechanisms, dysregulation, relationships to neonatal morbidity, mortality, and with searching for and developing new methods for early diagnosis of the cardiovascular dysregulation.

\section{DETERMINANTS OF CARDIAC CHRONOTROPIC CONTROL}

\section{Heritability}

Heritability determines many vital characteristics including heart rate (HR) and heart rate variability (HRV) through determination of development and functions all structures and molecules involved in cardiac activity control, including receptors, neurotransmitters, autonomic nervous system, etc. Therefore, the heritability can play major role in determination of cardiac chronotropic characteristics.

Singh and co-workers (1) assessed the impact of heritability and environment (household effects) on HR and HRV in a large number of families. Heritability analysis was done by studying correlations between siblings and spouse pairs. After adjusting for

Address for correspondence:

Kamil Javorka, Prof., MD., DSc. Department of Physiology, Jessenius Faculty of Medicine, Comenius University, Mala Hora N.4, 03601 Martin, Slovakia. e-mail: javorka@jfmed.uniba.sk 
covariates, the correlations were consistently higher among siblings $(0.21-0.26)$ compared with spouses $(0.01-0.19)$. The measured covariates in general accounted for $13 \%$ to $40 \%$ of the total phenotypic variance, whereas genetic factors accounted for $13 \%$ to $23 \%$ of the variation among HR and HRV measures.

Even greater genetic determination of RR intervals was found by other authors. Kupper et al. (2) studied 780 healthy twins and siblings. RR intervals and thus the heart rate (HR) were genetically determined from 37 to $48 \%$, respiratory sinus arrhythmia (RSA) from $40 \%-55 \%$. The importance of genetic factors to the HRV significantly increases at rest and during night, the covariance between respiration rate and RSA in these conditions was completely determined by common genes. Using univariate and multivariate statistical analysis, Uusitalo et al. (3) found that genetic factors accounted for a major portion $(31-57 \%)$ of the interindividual differences in HRV.

The influence of genotype on HR and HRV is highly complex due to complexity of cardiovascular regulation. This is why the exact genes determining HRV are not definitively known. Martin et al. (4) who estimated the heritability of resting heart rate to be $26 \pm 5 \%$ in healthy subjects, obtained evidence of linkage for the HR on chromosome 4 . This signal is in the same region as a quantitative trait locus (QTL) for long QT syndrome. There are two strong candidate genes: ankyrin-B (ANKB) and myozenin 2 (MYOZ2). Ankyrin promotes targeting of ion channels to the proper membranes in cells, myozenin 2 may indirectly (through calcineurin activation) influence calcium signalling and pacemaker function.

Other authors (5) identified in mice a significant quantitative trait locus (QTL) for HR on chromosome 6, QTL for total power (TP) HRV on chromosomes 2, 4, 5, 6, 14, for low frequency band (LF) on chromosome 16 and for high frequency band activity on chromosome 5, 2,11 and 15. Attention was focused on the gene for neurotransmitter acetylcholine, for the choline transporter gene, as well as the adrenergic receptors (6) and the $\mathrm{D}_{5}$ dopamine receptor (5).

Recently the list of candidate genes for determination chronotropic cardiac regulation is not definitive. But it is clear, that heritability plays an important role in determination of cardiac regulation in healthy humans and may explain a substantial proportion of the interindividual variance in HR and HRV.

\section{„Tracking phenomenon“}

DiPietro et al. (7) found that the dynamic parameters of fetal circulation, and some maternal physiological parameters (blood pressure, blood oxygen saturation) correspond to the $40-48 \%$ for the characteristics of heart rate (HR) and heart rate variability (HRV) in newborns and infants up to the end of the first year of life. Increased fetal heart rate is reflected in a higher mean heart rate in the newborns. Significant intraindividual stability of heart rate nad HRV were found not only during the prenatal period (fetal HR and HRV were measured and evaluated longitudinally from 20 through 38 weeks of gestation) but up to the postnatal age two (9). Even a small but significant relation has been shown between prenatal and postnatal heart rate at age ten (8). It indicates some "stability“ (inertia) of the cardiovascular parameters characteristics - tracking phenomenon - which transmits some characteristics from prenatal to postnatal life, of course, also on the base of the genetic determinants.

In the following paper, DiPietro et al. (8) investigated also whether fetal HR and HRV are useful predictors of child developmental outcome. They hypothesized that slower HR and higher level of variability would be reflected in more advanced development of functions in early childhood. They found that fetuses with slower and more variable heart rates (greater HRV) had latter - at age 2 years - significantly higher Mental and Psychomotor Development Index (MDI, PDI) and better language development than those with faster and more fixed heart rates. Similar results - associations between vagal tone and neonatal attentional orientation have been shown by Feldman (10), between HRV and MDI scores at 1 year by Richards (11), and between respiratory sinus arrhythmia and standardized cognitive test scores in middle childhood by El-Sheikh and Buckhalt (12). 
All these data suggest that magnitude and development (trajectories) of fetal heart rate variability during prenatal life correspond (to a certain level) with maturation of CNS including of autonomic nervous system and with mental and psychomotor development of individuals. It seems that features of the fetal HRV, and due to the tracking phenomenon also neonatal HRV, may provide chance to indirectly assess the nervous system development.

\section{Age}

Studies about the relationship between HR, HRV and gestational, respectively postnatal or postconceptional age have shown that the lower are these ages, the higher is mean heart rate and the more reduced is HRV. It is very likely that these findings relate to the maturity of individual components of the chronotropic controller incl. the autonomic nervous system (13). Therefore, when interpreting the results of HRV analysis in newborns, it must be taken into account this age determinant and results should be evaluated regarding appropriate values for each (gestational/postconceptional) age group. For newborns, reference values of longterm HRV were published by Mehta et al. (14), values obtained by spectral analysis of shortterm HRV are in papers of Kantor and Javorka (15), Lehotska et al. (16) and Yang et al. (17).

Gestational age - prematurity: Premature newborns have regulations of functions programmed primarely for appropriate development in the intrauterine environment and thus they are not completely adapted to the physiological demands of extrauterine life (18). Premature infants have a reduced HRV even without any sign of maladaptation to extrauterine life. Aarimaa and Oja (19) found in full term healthy newborns that in HRV was initially present the peak spectral activity in the low-frequency (LF) band (with sympathetic component) and later, at 5th postnatal day, appeared peak spectral activity also in the HF (parasympathetic) band. In healthy preterm infants was present in the 5th postnatal day just LF peak, with no significant activity in the HF band even during quiet NREM sleep. This deficit is possibly associated with the immaturity of the autonomic nervous system. Maturation of CNS/ANS is then accompanied by an increase HRV due to enhancement of parasympathetic (HF) activity $(20,21,22)$. As can be seen, the biggest difference in HRV between the premature and full term newborns is reduced or completely absent activity in HF parasympathetic band.

Postnatal age: The development of autonomic innervation of the heart, which affects the heart rate and HRV is not yet completed after birth. Parasympathetic tone is weak, and this is reflected in a higher resting mean heart rate. In results of HRV spectral analysis is typical dominance of activity in low-frequency band with sympathetic component. Some role can play also postnatal stress. Although transfer of results from animal experiments to human physiology must be done very carefully, experiments on newborn lambs showed that only on the third postnatal month is developed noticeable effect of the parasympathetic regulation on cardiac function (23). However, in human newborns even in the first postnatal days were elicitable cardiac inhibitory reflexes, for example oculocardiac and Cushing's reflex (24; Fig.1). These reflexes resulting in bradycardia may have a physiological role in rapid adaptation of coronary perfusion and heart metabolism at normal vaginal delivery when the fetal head is squeezed and retroorbital and intracranial pressures are increased.

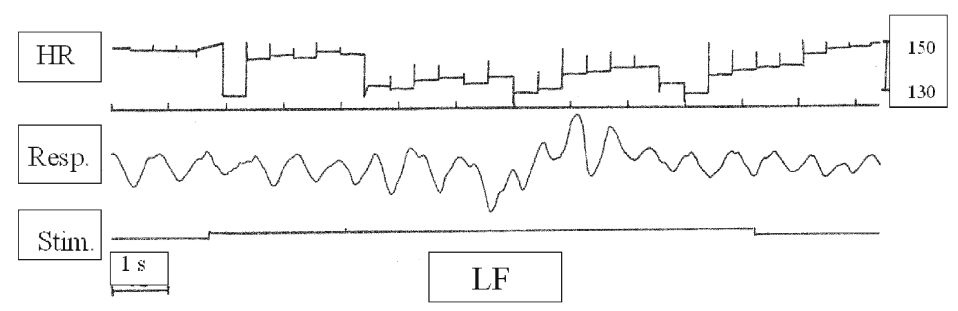

Fig. 1 Changes in instantaneous beat-to-beat heart rate (HR) and respiratory movements (Resp.) in premature newborn elicited by stimulation - pressure applied on large fontanelle. Cushing reflex-like bradycardic reaction. 
During the first postnatal days, the development of body systems including their control mechanisms is accelerated. HRV parameters significantly increase in all bands reflecting sympathetic and parasympathetic regulation in the first three postnatal days (25). The rapid development of HRV in full term healthy newborns was confirmed by spectral analysis as well as by another methods - Poincaré and sequence plots in the first 4 days $(26,27)$. The cited authors observed up twofold increase in the time and frequency domain HRV parameters, as well as an increase in the size of Poincaré plot reflecting the enhancement of HRV during the early postnatal period.

A possible explanation for the increase in HRV may be postnatal acceleration of maturation. Another explanations, which can be done in combination with the first one are 1) an impact of the onset of air breathing after birth with enhancement of the respiratory sinus arrhythmia and 2) gradual withdrawal of postnatal stress.

Postconceptional age (PCA): Postconceptional age is calculated as gestational age plus postnatal age (PCA = GA + PNA). It is a function of both, gestational and postnatal ages . HRV in relations to postconceptional age was studied by Yang et al. (17). They found that as the postconceptional age advanced, that exerts a significant influence over HRV with a steady increase in total power and in the both LF and HF bands, along with a progressive decline of LF/HF ratio (sympathovagal balance). Newborns of more than 36 weeks PCA demonstrated a significantly greater chronotropic regulatory activity of ANS than the younger group. The maturation of sympathovagal balance needed to take two more weeks with a $\mathrm{LF} / \mathrm{HF}$ ratio cut-off age occurring at 38 weeks PCA. It means that newborns with PCA more than 38 weeks are relatively mature for neonatal conditions in terms of sympathovagal balance.

\section{Gender}

In adulthood, there are sex differences in the mean heart rate and HRV (e.g. 28). Adult females of childbearing age have a higher HR by 3-7 per min compared with men.

Some papers deal the question whether these sex differences in the HR and HRV are already present at birth or develop later. The results of the studies on gender differences in HR and HRV in newborns are not uniform. Kero (29) and Yang et al. (17) in premature infants, and Harper with co-workers (30) in full term newborns and infants did not find any significant gender differences in heart rate. On the other hand, Javorka and Zavarska (31) and Nagy et al. (32) found that boys have, on average, by 5, resp. 7 beats per minute significantly lower mean heart rate compared with girls. Lehotska and Javorka $(26,27)$ found marginally no significant differences in the average duration of RR intervals: male newborns tended to a higher value of RR intervals (RR intervals in boys: 501 $\pm 13 \mathrm{~ms}$, in girls: $461 \pm 13 \mathrm{~ms} \mathrm{p}=0.051$ ), i.e. slightly lower mean HR. HRV parameters did not differ between boys and girls.

Potential higher heart rate in girls could be associated with distinct morphological and functional parameters of CVS, as the size of the heart, stroke volume, and so, therefore, not only directly related to the endocrine sex differences.

\section{Nutrition. Small for Gestational Age (SGA) newborns}

Nutrition and growth can play important role in cardiovascular system functions. This is why some authors studied in detail the relationship between intrauterine growth reflected in size and weight of newborns and HR/HRV.

Spassov et al. (32) examined HR and HRV in small for gestational age (SGA) newborns born in 37 - 41 gestational week during sleep. In both, REM as well as NREM, SGA newborns differed from appropriate for gestational age (AGA) newborns by shorter RR intervals (higher mean HR) and reduced HRV in all bands.

The parameters of the HR and HRV in SGA newborns are influenced mainly through sympathetic activity in early postnatal period (33). Lehotska et al. (34) observed in SGA newborns a tendency for a higher mean heart frequency. Taking into account that au- 
tonomic nervous system is an important regulator of metabolism and energetic balance and SGA group has higher metabolic rate per kg of weight, these factors can explain physiological role of the higher HR in SGA newborns.

Results of time and spectral frequency analysis of the HRV and Poincare plot in the 1st and 4th postnatal days have shown no differences between SGA and AGA newborns. Significant differences between these two groups in HRV during the first neonatal day of life were found only by sequence plot method (27).

\section{Sleep}

During sleep, significant changes in activities occur not only in CNS, but also in other systems, including cardiovascular and respiratory. In adults, during NREM sleep, there is usually more regular breathing with unchanged respiratory rate but diminished tidal volumes resulting in higher $\mathrm{PaCO}_{2}$ and a small decrease in $\mathrm{PaO}_{2}$ (by 5 and $2 \mathrm{mmHg}$ on average). In REM sleep, the breathing is irregular and accelerated.

Regarding HRV, in adults during NREM compared to REM sleep is a decrease in HRV total power due to reduction of activities in VLF and LF bands. Activity in HF band can be increased, unchanged, or decreased according to a change of breathing pattern. In REM sleep, activity in the VLF and LF bands in contrast to HF rises resulting in significant increase of LF/HF ratio. An interesting finding was found out by Busek et al. (36) that the ratio LF/HF increases even just before the onset of REM phase. It indicates potential importance of ANS activity changes for sleep organization, which can be not only an accompanying phenomenon but also one of the factors causing changes in sleep organization.

Influence of sleep stages on HRV in infants was studied by several authors (e.g. 20,21,37). HRV measures are affected by sleep state in different ways. During quiet NREM sleep, newborns had lower mean HR as well as parameters of the HRV compared with awake state (20). However, during REM sleep the HRV parameters were similar to the „awake“ HRV. Porges et al. (21) found in newborns in NREM sleep significantly longer RR intervals but increased amplitude of the HRV mainly in the HF band influenced by respiratory sinus arrhythmia (RSA). Enhancement of the RSA may be related to breathing pattern in non-REM sleep.

For quantification nonlinear HRV during different sleep stages used Vandeput et al (38) the numerical noise titration technique. Periods of NREM sleep have significantly lower noise limit values, which means that the RR interval series are in this stage less chaotic. The authors state that using this technique of HRV evaluation, periods of NREM sleep can be distinguished from periods of REM sleep and from total recording period.

\section{Spontaneous Breathing and Artificial Ventilation}

Breathing pattern (mainly respiratory rate and depth) greatly affects HR and HRV, especially HF band reflecting respiratory sinus arrhythmia (RSA). RSA as the relationship between breathing and heart rate is a manifestation of physiological regulation of cardiovascular and respiratory systems and their links.

In newborns the mean respiratory rate is about $40-60 / \mathrm{min}$ and gradually decreases by postnatal age. Often, typically in premature infants is irregular or periodic. The more immature is a newborn the higher is occurrence of the periodic breathing.

In a slow and deep breathing is enhanced parasympathetic HF band, which is under the influence of RSA. These changes also occur in newborns who have typical dominant activity in LF band. Baldzer et al. (39) examined the relationship between heart rate and breathing pattern in healthy full term newborns in the first postnatal days during a quiet sleep. For children with lower respiratory rate, RSA accounted for more than $20 \%$ of the total power, and ratio LF/HF was less than 4 . The second group of 
newborns with higher respiratory rate had reduced power in HF band (RSA) and LF/ $\mathrm{HF}$ ratio was greater than 4 .

HRV is affected also by the artificial ventilation, by frequency of ventilation (Fig.2) and tidal volume. Even in premature infants with respiratory distress syndrome (born in 33rd gestational week ) during the first 3 postnatal days, artificial ventilation induced enhancement of HF band (RSA) in spectral HRV (40). This artificially elicited „RSA“ can occur even in severely immature infants (a case of newborn of gestational age 28.5 weeks, weight $940 \mathrm{~g}$ described by Zernikow and Michel; 41). This finding suggests that parasympathetic part of the autonomic nervous system may be in some preterm infants more mature as expected.

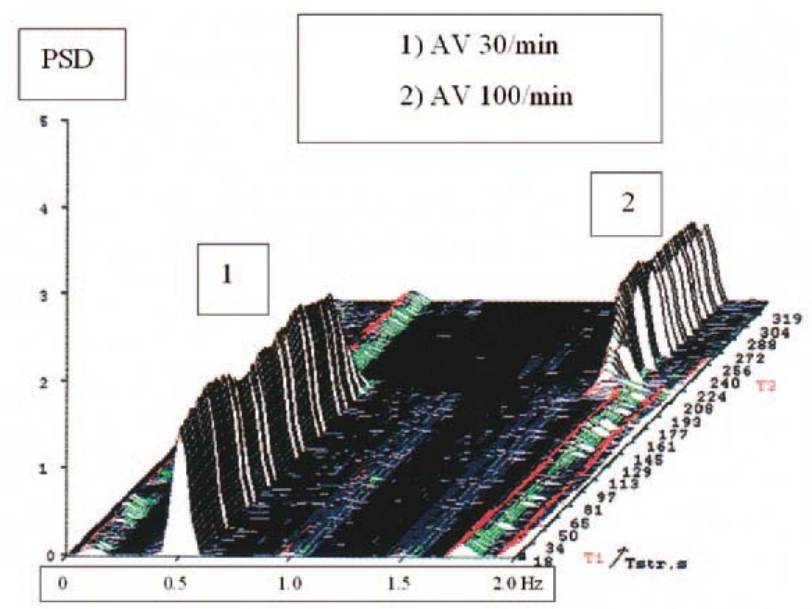

Fig. 2 Power spectral density (PSD) of HRV in anaesthetized paralyzed rabbit artificially ventilated with frequencies: 1) 30/min (0.5 Hz) and 2) 100/min (1.66 Hz). Frequency of spectral activity (X axis) corresponds to ventilatory frequencies - RSA

\section{PECULARITIES OF THE CARDIAC ACTIVITY REGULATION IN NEWBORNS}

\section{Intracardiac and extracardiac regulations}

Regulation of cardiac activity in fetuses and newborns has its own pecularities. All the specificities of the cardiac regulation determine basal heart rate, HRV and heart rate reactions to various stimuli in newborns.

Intracardiac autoregulation - heterometric (Frank and Starling law) and homeometric (depending on the frequency) is functioning already in fetuses and newborns , but the curve - relationship between end-diastolic volume and myocardial contraction force (Fig. 3) is shifted to the upper limit (42). Therefore, the homeometric mechanism - dependence between heart rate and cardiac output - seems to be more important for cardiac regulation. It follows that changes in heart rate in fetuses and newborns cause relatively more important changes in cardiac output compared with older children and adults. 


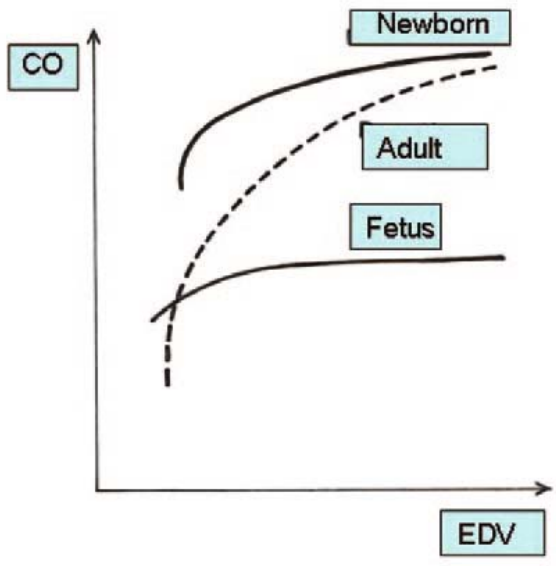

Fig. 3 Relationship curves between end-diastolic volume (EDV) and cardiac output (CO) in newborn, adult and fetal subjects. Modified from Rudolph (42)

Also extracardiac regulation in fetal and early postnatal life is realized with certain pecularities: Baroreflexes are in function in fetuses as well as in newborns, however they are less important in comparison to later postnatal life, and their sensitivity is reduced. Opinions that in the baroreflex sensitivity (BRS) reduction an important role plays immaturity of the baroreflex arc are based on the findings that BRS increases with postnatal age faster in term than in preterm infants (43). BRS rises progressively with postnatal age, and in 3rd - 6th months (according to maturity at birth) reaches values comparable to the adults $(44,45)$.

Chemoreflexes: The fetuses have more active aortic than carotid peripheral chemoreceptors (46). After birth, the start of extrauterine breathing and significant change in $\mathrm{PaO}_{2}$ reset sensitivity of peripheral chemoreceptors to new values of $\mathrm{PaO}_{2}$. This transient state lasts some time (up two weeks). During this lag time physiological role of the peripheral chemoreceptors in regulation of cardiorespiratory functions is diminished and the chemoreceptors become increasingly more oxygen-sensitive. Approximately, by 2 weeks of postnatal age, peripheral chemoreceptor activity is similar to that of adults. Regarding central chemoreceptors - term infants have already adult-like activity at birth, whereas preterm infants take 4 weekes to achieve their level of response (47).

Both chemoreceptor types (central and peripheral) are crucial for regulation of breathing, however, the circulation may be influenced, too. This influence is direct and indirect (through ventilatory changes). Changes in heart rate during stimulation of peripheral chemoreceptors by hypoxia is modified via baroreflexes by hypertensive response due to redistribution of circulating blood. This is why the primary tachycardic response is usually replaced by bradycardia in hypoxia.

\section{Cardiac reflexes}

Pecularities in chronotropic cardiac regulation determined by above described factors influence also complex cardiovascular reflexes in newborns. Evaluation of these reflexes is complicated by absence of voluntary cooperation of examined subjects - newborns, and therefore by inability to apply some examination methods normally used in older children and adults:

Ewing's battery of cardiovascular tests. From the Ewing's battery, the most proven cardiovascular tests for examination of cardiac chronotropic regulation are deep breathing, orthostatic and Valsalva tests. Nevertheless, deep breathing test and Valsalva test require voluntary cooperation of the examined subject and they cannot be applied in newborns. 
Rarely, a modified orthostatic test was studied in newborns $(48,49)$. Passive head up tilting to $+45^{\circ}$ and $90^{\circ}$ used Andrasyova and Kellerova (50) in full term newborns in postnatal age 1-7 days. From the first day was present an increase of HR in the orthostasis. The increases of all studied cardiovascular parameters (HR as well as systolic and diastolic blood pressure) were present only in 4- to 7-day-old newborns. It seems that the development in the reactivity of cardiovascular system becomes apparent after a relative stabilization of the neonatal blood volume on the $2^{\text {nd }}-3^{\text {rd }}$ postnatal day.

Cardiovascular reactions to orthostasis were delayed and prolonged in cocaine-exposed neonates indicating alteration of the development of sympathetic and parasympathetic systems after prenatal cocaine exposure (51).

In newborns were studied also other cardiovascular tests: cold face test (44), oculocardiac and Cushing reflex (52), chronotropic responses accompanying orientation and defense responses (31), etc. Results have shown that healthy newborns can react to various stimuli by heart rate changes according to the degree of development and maturity.

Unfortunately, methodology, standardization and interpretation of the mentioned CV tests are not well established for neonatology. That is why new methods (for example HRV evaluated in time and frequency domains and by nonlinear methods) that would not require voluntary cooperation of the examined subject should be studied and developed.

\section{CONCLUSIONS}

Heart rate and heart rate variability is determined by many factors. Major factor is heritability followed by „tracking phenomenon“. Factor of prematurity is demonstrated by higher HR and reduced HRV with significant dominancy of sympathetic activity (LF band in HRV). During the first postnatal days, HRV parameters significantly increase reflecting maturation of the autonomic nervous system and some physiological changes (breathing pattern, etc.). Influence of gender and nutrition (hypotrophy, SGA) on HR and HRV in newborns is not significant, however tendency to higher HR in girls and in SGA can be seen. In NREM sleep are significantly longer RR intervals and enhanced HRV mainly in parasympathetic HF band (reflecting respiratory sinus arrhythmia - RSA) in relation to changed breathing pattern. Respiratory rate and tidal volumes during spontaneous breathing affect HR and spectral activity in HRV - HF band. It can be seen also during artificial ventilation of newborns. Regulation of cardiac activity in newborns has its own specific features. Dominant mechanism in autoregulation is mechanism depending on the heart rate. Baroreflexes in newborns have reduced sensitivity (BRS), which rises progressively with postnatal age. The values of BRS for preterm newborns are lower than the values for full term babies. Newborns have active cardiovascular reflexes for maintaining of adequate perfusion of organs according to conditions. Maturation of the cardiovascular regulation in early postnatal period is reflected in changes of some reflexes like of the orthostatic reflex.

\section{REFERENCES}

1. Singh JP, Larson MG, O`Donnell CJ, Tsuji H, Evans JC, Levy D. Heritability of heart rate variability. The Framingham Heart Study. Circulation 1999; 99: 2251 - 2254.

2. Kupper N, Willemsen G, Posthuma D, de Boer D, Boomsma DI, de Geus EJC. A genetic analysis of ambulatory cardiorespiratory coupling. Psychophysiology 2005; 42: 202 - 212.

3. Uusitalo AL, Vanninen E, Levälahti E, Battié MC, Videman T, Kaprio J. Role of genetic and environmental influences on heart rate variability in middle-aged men. Am J Physiol Heart Circ Physiol 2007; 293 (2): H1013- H1022. 
4. Martin L, Comuzzi AG, Sonnenberg GE, Myklebust J, James R, Marks J, Blanger J, Kissebach AH. Major quantitative trait locus for resting heart rate maps to a region on chromosome 4. Hypertension 2004; 43: $1146-1151$.

5. Howden R, Liu E, Miller-DeGraff L., Keener HL, Walker Ch, Clark JA, Myers PH, Rouse DC, Wiltshire T, Kleeberger SR. The genetic contribution to heart rate and heart rate variability in quiescent mice. Am J Physiol Heart Circ Physiol 2008; 295:H59-H68.

6. Neumann SA, Lawrence EC, Jennings JR, Ferrell RE, Manuck SB. Heart rate variability is associated with polymorphic variation in the choline transporter gene. Psychosomatic Med 2005; 67: 168 - 171.

7. DiPietro JA., Costigan KA., Pressman EK., Doussard-Rooswelt JA. Antenatal origins of individual differences in heart rate. Dev Psychobiol 2000; 37: 221-228.

8. DiPietro JA, Bornstein MH, Hahn C-S, Costigan K, Achy-Brou A. Fetal heart rate and variability: Stability and prediction to developmental outcomes in early childhood. Child Dev 2007; 78(6): 1788-1798.

9. Thomas PW, Haslum MN, MacGillivray I, Golding MJ. Does fetal heart rate predict subsequent heart rate in childhood? Early Hum Develop 1989; 19:147-152.

10. Feldman R. From biological rhythms to social rhythms: Physiological precursors of mother-infant synchrony. Devel Psychol 2006; 42:175-188.

11. Richards JE. Development and stability in visual sustained attention in 14, 20, and 26 week infants. Psychophysiol 1989; 26: 422 - 430.

12. El-Sheikh M, Buckhalt JA. Vagal regulation and emotional intensity predict children's sleep problems. Developm Psychobiol 2005; 46: 307 - 317.

13. Van Ravenswaaij-Arts CMA, Hopman JCW, Koléée LAA, Stoelinga G, Van Geijn H. Spectral analysis of heart rate variability in spontaneously breathing very preterm infants. Acta Paediat 1994; 83: $473-480$.

14. Mehta SK, Super DM, Connuck D, Salvator A, Singer L, Fradley LG, Harcar-Sevcik RA, Kirchner HL, Kaufman ES: Heart rate variability in healthy newborn infants. Am J Cardiol 2002; 89:50-53.

15. Kantor L, Javorka K. Jakou variabilitu srdeční frekvence mají zdraví novorozenci? Proceedings: Variabilita srdeční frekvence a její hodnocení $v$ biomedicínskych oborech - od teorie ke klinické praxi. Olomouc, 2003. p. 30- 34.

16. Lehotska Z, Javorka K, Javorka M, Zibolen M, Luptakova A. Heart rate variability in small-for-age newborns during first days of life. Acta Med Mart 2007; 7: 10-16.

17. Yang TF, Kao NT, Chan RC, Kuo TBJ, Chen AJ. Power spectrum analysis of heart arte variability in full term and preterm infants. Tw J Phys Med Rehabil 2007; 35(3): 127-135.

18. Sweeney JK. Physiologic adaptation of neonates to neurological assessment. Phys Occup Ther Pediatr 1986; 6:155-169.

19. Aarimaa T, Oja R. Transcutaneous $\mathrm{pO} 2, \mathrm{pCO} 2$ and heart arte patterns during normal postnatal adaptation and respiratory distress. Early Hum Developm 1988; 16: 3-11.

20. Curzi-Dascalova L, Christova E, Peirano P, Singh BB, Gaultier C, Vincente G. Relationship between respiratory pauses and heart rate during sleep in normal premature and full term newborns. J Developm Physiol 1989; 11: $323-330$.

21. Porges SW, Doussard-Rooswelt JA, Stifter CE, McClenny BD, Riniolo TC: Sleep state and vagal regulation of heart periods in human newborn: An extention of the polyvagal theory. Psychophysiology 1999; 14: 14-21.

22. Longin E, Gerstner T, Scaible T, Lenz T, Konig S. Maturation of the autonomic nervous system: Differences in heart rate variability in premature vs. term infants. J Perinat Med 2006; 34: 303-308.

23. Minoura S, Gilbert RD. Postnatal change of cardiac function in lamb: Effects of ganglionic block and afterload. J developm Physiol 1987; 9: 123 - 135.

24. Javorka K., Zavarska L. Okulokardialny reflex u nedonosenych deti. Csl Pediat 1978; 33: 138 - 140.

25. Kantor L, Curtisova V, Dubrava L. Development of heart rate variability during the first three days of life. Acta Med Mart. 2003; 3: 22-29.

26. Lehotska Z. Variabilita frekvencie srdca u donosenych hypotrofickych novorodencov. Doktorandska dizertacna praca. Martin. 2007, 90 p.

27. Javorka M. Použitie niektorych metod nelinearnej dynamiky na hodnotenie variability parametrov kardiovaskularneho systemu. Habilitacna praca. Martin. 2006, 110 p.

28. Javorka K, Calkovska A, Danko J, Dokus K, Funiak S, Gwozdziewicz M, Javorka M, Javorkova J, Kuchta M, Misovicova N, Ondrejka I, Salinger J, Stejskal P, Tonhajzerova I, Zubor P. Variabilita frekvencie srdca:Mechanizmy, hodnotenie, klinicke vyuzitie. Martin, Osveta. 2008, 191 p.

29. Kero P. Heart rate variation in infants with the respiratory distress syndrome. Acta Paed Scand 1974; $70 \mathrm{p}$.

30. Harper RM, Hoppenbrouwers T, Sterman MB, McGinty DJ, Hodgman J. Polygraphic studies of normal infants during first six months of life. Heart rate variability as a function of state. Ped Res 1976; 10: 945-948.

31. Javorka K, Zavarska L. Zmeny frekvencie srdca pocas orientacnej a obrannych reakcii u nedonosenych deti. Csl. Pediatr. 1978, 33 (6): 335-339. 
32. Nagy E, Orvos H, Bardos G, Molnar P. Gender-related heart rate differences in human neonates. Ped Research 2000; 47: $778-780$

33. Spassov L, Curzi-Dascalova L, Clairambault J, Kauffman F, Eiselt M, Madigue C, Peirano P. Heart rate and heart rate variability during sleep in small-for-gestational age newborns. Pediatr Res 1994; 35: 500 - 505.

34. Massin MM, Withofs N, Mayens K, Ravet F. The influence of fetal and postnatal growth on heart rate variability in young infants. Cardiology 2001; 95: 80-83.

35. Lehotska Z, Javorka K, Javorka M, Zibolen M, Krupičková S. Variabilita frekvencie akcie srdca (VFS) a specifika jej vysetrenia v novorodeneckom obdobi. Csl Pediat 2007; 62: 98-104.

36. Busek P, Vankova J, Opavsky J, Salinger J. Nevsimalova S. Spectral analysis of the heart variability in sleep. Physiol Res 2005; 54: 369-376.

37. Doyle OM, Korotchikova I, Lightbody G, Marnane W, Kerins D, Boylan GB. Heart rate variability during sleep in healthy term newborns in the early postnatal period. Physiol Meas 2009; 30 (8): $847-860$

38. Vandeput S, Naulaers G, Daniels H, Van Huffel S. Heart rate variability during REM and non-REM sleep in preterm neonates with and without abnormal cardiorespiratory events. Early Hum Developm 2009; 85: 665 - 671.

39. Baldzer K, Dykes FD, Jones SA, Brogan M, Carrigan TA, Giddens DP. Heart rate variability analysis in full term infants: spectral indices for study of neonatal cardiorespiratory control. Pediatr Res 1989; 26:188-195.

40. Van Ravenswaaij-Arts CM, Hopman JC, Kollee LA, Stoelinga G, Van Geijn H. The influence of arteficial ventilation on heart rate variability in very preterm infants. Pediatr Res 1995; 37: 124-130.

41. Zernikow B, Michel E. Ventilator-associated sinus arrhytmia in preterm neonate - an indicator for a mature autonomic nervous system. Acta Paediatr 1996; 85: 505-507.

42. Rudolph AM. Venous return and cardiac output in the perinatal period. Cardiovascular and Respiratory Physiology in Fetus and Neonate. Colloq. INSERM John Libbey Eurotext. Montrogue. 1986; 133: $15-30$.

43. Gournay V, Drouin E, Rozé J-C. Development of baroreflex control of heart rate in preterm and full term infants. Arch Dis Child Fetal Neonatal Ed 2002; 86: F151 - F154.

44. Harrington C, Kirjavainen T, Teng A, Sullivan CE. Cardiovascular responses to three simple, provocative tests of autonomic activity in sleeping infants. J Appl Physiol 2001; 91: 561-568.

45. Yiallourou SR, Sands SA, Walker AM, Horne RSC. Postnatal development of baroreflex sensitivity in infancy. J Physiol 2010; 588 (12): 2193 - 2203.

46. Wennergren G, Wennergren M. Respiratory effects elicited in newborn animals via the central chemoreceptors. Acta Physiol Scand 1980; 108: 309 - 311.

47. Blackburn ST. Maternal, fetal and neonatal physiology: A clinical perspectives. 3rd Edition. Saunders. 2007, 800 p.

48. Javorka K.Posturalne zmeny dychania a tlaku krvi u nedonosenych novorodencov. Bratisl lek Listy 1992; 93: 346-351.

49. Kantor L. Variabilita srdecni frekvence $u$ zdravych novorozencu. Fyziologicke hodnoty a vyvoj behem prvnich trech dnu zivota. Olomouc. 2003. Doktorandska dizertacni prace na Univerzite Palackeho v Olomouci. 2003.

50. Andrasyova D, Kellerova E. Blood pressure and heart rate response to head-up position in full term newborns. Early Hum Developm 1996; 44(3):169 - 178.

51. John V, Dai H, Talati A, Chamigo RJ, Neuman M, Bada HS. Autonomic alterations in cocaine-exposed neonates following orthostatic stress. Pediatr Res 2007; 61(2): 251-256.

52. Javorka, K, Zavarska, L. Okulokardialny reflex u nedonosenych deti. Csl Pediatr 1978; 33 (3): 138-140.

Acknowledgement: This work was supported by Project VEGA N. 1/0073/09

Received: June 27, 2011

Accepted: August 8, 2011 